\title{
Transplantation of cryopreserved fetal ovarian tissue to adult recipients in mice
}

\author{
S-L. Cox ${ }^{1}$, J. Shaw ${ }^{2}$ and G. Jenkin ${ }^{1,2}$ \\ ${ }^{1}$ Department of Physiology and ${ }^{2}$ Institute of Reproduction and Development, Monash University, Clayton, \\ Victoria 3168, Australia
}

\begin{abstract}
Sixteen-day-old fetal mouse ovaries were slowly frozen in 1.5 mol dimethylsulfoxide $\mathrm{ml}^{-1}$ and subjected to one of two thawing procedures - fast thaw or slow thaw. Fresh and frozen-thawed fetal ovaries were transplanted orthotopically (to the bursal cavity) to either bilaterally or unilaterally ovariectomized adult female recipients. Fresh fetal ovaries were also transplanted heterotopically (under the kidney capsule) to intact, bilaterally or unilaterally ovariectomized adult females. Transplantation of fetal ovaries to bilaterally ovariectomized adult recipients resulted in restoration of cyclic activity within $20.5 \pm 4.7$ (mean \pm SEM) days or $23.4 \pm 0.8$ days in orthotopic and heterotopic groups, respectively. Developing follicles and corpora lutea were observed within 4 weeks after transplantation of fetal ovaries to heterotopic sites and within 6 weeks after transplantation to orthotopic sites. After orthotopic transplantation, $33 \%$ of the recipients became pregnant. Orthotopic or heterotopic transplantation to intact of unilaterally ovariectomized recipients resulted in quiescence of the fetal ovary. After cryopreservation, transplantation of fetal ovaries to bilaterally ovariectomized recipients resulted in restoration of cyclic activity within $19.3 \pm 2.1$ days and 23.4 \pm 5.1 days after transplantation in slow thaw and fast thaw groups, respectively. Fertility was restored to $86 \%$ of fast thawed and $25 \%$ of slow thawed fetal ovary transplants to bilaterally ovariectomized adult recipients. No ovarian tissue was observed on the side of the fetal graft in unilaterally ovariectomized recipients that received frozen-thawed fetal ovaries. These results demonstrate that cryopreserved fetal ovarian tissue can be transplanted to adult recipients with subsequent restoration of fertility and that this process is dependent on the absence of the ovaries of the recipients.
\end{abstract}

\section{Introduction}

The transplantation of ovarian tissue has been used as a method of enhancing the understanding of the control of ovarian function as well as improving the reproductive performance of females. The role of the endocrine environment of the host in the survival of transplanted ovarian tissue is not fully established. Studies on the effect of ovariectomy on graft survival have produced conflicting results. Studies of ovarian tissue grafted to recipients with one or both of their ovaries intact have reported either retarded (Deanesly, 1956) or normal (Carroll et al., 1991) growth. Studies in which ovarian tissue was transplanted to recipients with high endogenous gonadotrophin concentrations have also reported conflicting results. Although the majority of these studies found that grafts develop after transplantation (Deanesly, 1956; Ben-or, 1965; Carroll et al., 1991; Candy et al., 1995), other investigations showed that ovarian tissue did not survive when transplanted to recipients with high concentrations of circulating gonadotrophins (Rumery and Blandau, 1976).
The likelihood of graft survival was increased by transplanting ovarian tissue to many sites of the body other than its normal anatomical position. Such sites have been chosen for their rich vascular supply or purported immunoprivilege and include subcutaneous tissue, the anterior chamber of the eye, the neck or the renal capsule (Robertson, 1942; Russell and Hurst, 1945; Deanesly, 1956; Jones and Krohn, 1960). The majority of transplants have been to the kidney since it has a high blood supply, receiving approximately $20 \%$ of the cardiac output from the heart (Sherwood, 1989) and increased concentrations of angiogenic growth factors (Jakeman et al., 1992). Grafting under the renal capsule, thus, provides an ideal site for rapid revascularization as well as ease of recovery and identification of grafts.

Transplantation procedures for ovarian tissue would be enhanced if the tissue could be successfully cryopreserved. Early attempts to cryopreserve adult mammalian ovarian tissue resulted in only $5 \%$ of the oocyte population surviving (Green et al., 1956), and primordial oocytes were virtually the sole survivors (Deanesly, 1954). The primordial oocyte may better withstand both cryopreservation and transplantation procedures owing to its peripheral location in the ovarian cortex, its small size, and its low metabolic activity (Gosden, 1992). 
The number of germ cells reaches its peak during fetal or early neonatal development in the mammalian ovary. By the time sexual maturity is reached, the number of germ cells remaining in the ovary has fallen markedly (Baker, 1971). Fetal ovaries may, thus, prove ideal for preservation of the female germ line by cryopreservation and transplantation since, at this stage, the ovary is very small and contains a minimal amount of stromal and connective tissue. Transplantation of fetal ovarian tissue to adult hosts has been reported in rats (Harris and Eakin, 1949; Mangoushi, 1974, 1977), mice (Russell and Douglass, 1945; Rumery and Blandau, 1976), rabbits (Holyoke, 1956), guinea pigs (Donovan and Peddie, 1973) and humans (Povlsen et al., 1974). Such studies have not been performed using cryopreserved fetal ovarian tissue. The possibility of using fetal ovarian tissue for cryobanking female germ cells has many potential scientific applications, including the storage of genetic material from valuable, rare or endangered species. The aim of this study was to develop a cryopreservation procedure for fetal mouse ovaries and to investigate factors that affect the establishment of fetal mouse ovaries in adult female recipients.

\section{Materials and methods}

\section{Animals}

Six- to eight-week-old Balb/c inbred female mice $(n=116)$ were used as recipients. Thirty-five pregnant $\mathrm{Balb} / \mathrm{c}$ females at day 16 of gestation were used for the collection of fetal ovaries. Thirty intact and 20 vasectomized 6-8-week-old $\mathrm{Balb} / \mathrm{c}$ males were used for mating studies. All mice were obtained from the Central Animal House at Monash University, and housed under a $12 \mathrm{~h}$ light: $12 \mathrm{~h}$ dark regimen at $22^{\circ} \mathrm{C}$. Ethical approval for these studies was obtained from the Standing Committee on Ethics in Animal Experimentation, Monash University and conform with the conditions laid down by the $\mathrm{NH}$ and MRC/CSIRO/AAC Australian Code of Practice for the Care and Use of Animals for Scientific Purposes (1990).

\section{Collection of fetal ovaries}

Pregnant female inbred Balb/c mice were killed by cervical dislocation at day 16 of gestation. The fetuses were removed from the uterine horns and the size of the litter recorded (control litters). The fetuses were decapitated and the abdomen of the fetuses opened. The gonads were identified as either testes or ovaries by their appearance and location in the fetus. The fetal ovaries were dissected free and transferred to phosphate-buffered saline (PBS; Sigma, St Louis, MO) at room temperature until required for transplantation or freezing. The ovaries were randomly allocated to two treatment groups, unfrozen and frozen. Immediately, after collection, unfrozen fetal ovaries $(n=13)$ that were not transplanted were placed into Bouin's solution for $24 \mathrm{~h}$ after which they were processed for histological examination for subsequent comparison with treated ovaries.

\section{Cryopreservation of fetal ovaries}

Fifty-five fetal ovaries were slowly frozen using a modification of the method of Gosden et al. (1994). Briefly, the ovaries were suspended in a cryoprotectant solution of PBS, 10\% (v/v) fetal calf serum (FCS; Gibco, Gaithensburg) containing $1.5 \mathrm{~mol}$ dimethylsulfoxide $1^{-1}$ (DMSO; Sigma) at room temperature. Each ovary was then drawn up into the middle of a $0.25 \mathrm{ml}$ plastic freezing straw with a small volume of cryoprotectant solution. The straws were sealed with polyvinyl chloride powder and held on ice for $15 \mathrm{~min}$ before they were transferred to a programmable freezer (Cryologic Pty, Ltd, Melbourne) precooled to $0^{\circ} \mathrm{C}$. The straws were cooled at $2^{\circ} \mathrm{C} \mathrm{min}^{-1}$ to $-7^{\circ} \mathrm{C}$ and held for $10 \mathrm{~min}$ for seeding, which was carried out by touching the meniscus of the solution in the straw with a cold pair of forceps. The temperature was then lowered at $0.3^{\circ} \mathrm{C} \min ^{-1}$ to $-40^{\circ} \mathrm{C}$ and held for $30 \mathrm{~min}$, after which the straws were rapidly cooled at $10^{\circ} \mathrm{C} \mathrm{min}^{-1}$ to $-80^{\circ} \mathrm{C}$. The straws were then removed and plunged directly into liquid nitrogen and stored for up to 1 week.

The frozen ovaries were divided into two groups for thawing. The first group $(n=16)$ was placed on the bench for $90 \mathrm{~s}$ (slow thaw). The second group $(n=14)$ was thawed using a procedure adapted from Shaw et al. (1995a, b) which aimed to minimize the time the ovaries were in the temperature range at which ice crystallization and ice crystal growth occur. This was achieved by holding the straws horizontally at $-120^{\circ} \mathrm{C}$ in the vapour phase above liquid nitrogen for $2 \mathrm{~min}$ and then immersing them directly into a $37^{\circ} \mathrm{C}$ waterbath for 5-10 s until the solution had thawed (fast thaw).

The ovaries from both groups were expelled into a Petri dish

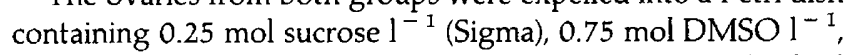
$10 \%(\mathrm{v} / \mathrm{v})$ FCS, PBS at room temperature for $10 \mathrm{~min}$. The fetal ovaries were then placed into a solution containing $0.25 \mathrm{~mol}$ sucrose $\mathrm{l}^{-1}, 10 \%(\mathrm{v} / \mathrm{v}) \mathrm{FCS}$, and PBS for $10 \mathrm{~min}$. Ovaries were selected randomly from both fast $(n=21)$ and slow thaw $(n=23)$ groups at this stage and transplanted or placed into Bouin's $(n=12)$ solution for histological examination.

\section{Transplantation procedure}

Orthotopic transplantation. The recipient mice were anaesthetized with $0.2 \mathrm{ml}$ Avertin $(2.5 \%$ solution of $1 \mathrm{mg}$ tribromoethanol and $0.5 \mathrm{mg}$ amylene hydrate (Aldrich, Milwaukee, WI) in distilled water). The ovariectomy procedure used was a modification of the method of Jones and Krohn (1960). Briefly, for unilaterally ovariectomized recipients, one of the ovaries of the recipient was removed by opening the bursa along the edge of the fat pad and removing the ovary at the hilum. One fetal ovary was then placed into the empty bursal cavity of the recipient and the bursa sewn up using $9 / 0$ non-absorbable suture thread (Novafil; Davis and Geck, Manati). The reproductive tract was then returned to its normal anatomical position and the abdominal wall and skin closed using 3/0 silk thread (Davis and Geck). For bilaterally ovariectomized recipients, both ovaries of the recipient were removed and one fetal ovary was transplanted into each empty bursal cavity.

Heterotopic transplantation. One fetal ovary was transplanted under the renal capsule of each recipient by creating a subcapsular pocket between the renal capsule and the renal parenchyma. One (in the case of unilaterally ovariectomized recipients) or both (in the case of bilaterally ovariectomized 
recipients) ovaries were removed by cautery at the top of each uterine horn. The intact recipients had both of their own ovaries remaining in situ.

Orthotopic transplantation of fresh 16-day fetal ovaries. Fifteen recipients were either bilaterally or unilaterally ovariectomized at the time of transplantation to establish whether the presence of the recipient's own ovaries influenced the development of transplanted 16-day-old fetal ovaries. One fresh fetal ovary was transplanted into each empty bursal cavity of the bilaterally ovariectomized recipients $(n=9)$ or a single fetal ovary was transplanted into unilaterally ovariectomized recipients $(n=7)$. The control group consisted of bilaterally ovariectomized adult females $(n=15)$ in which no fetal ovarian tissue was transplanted into the empty bursal cavity.

Heterotopic transplantation of fresh 16-day fetal ovaries. A 16-day-old fetal ovary was transplanted under the left renal capsule of intact $(n=24)$, bilaterally ovariectomized $(n=24)$ or unilaterally ovariectomized ( $n=24$ ) adult recipients to investigate whether the development of the transplanted fetal ovary was enhanced when transplanted to a site with a rich vascular supply. The control group ( $n=15$ ) consisted of bilaterally ovariectomized adult females who did not receive any fetal ovarian tissue.

Orthotopic transplantation of frozen-thawed 16-day fetal ovaries. In this experiment, the frozen fetal ovaries were subjected to one of two thawing procedures. Slowly frozen 16-day-old fetal ovaries from the fast thaw and slow thaw groups were transplanted to either bilaterally (fast thaw, $n=7$; slow thaw, $n=8$ ) or unilaterally (fast thaw, $n=7$; slow thaw, $n=7$ ) ovariectomized adult recipients.

\section{Assessment of function of transplanted fetal ovaries}

Orthotopic groups. Bilaterally ovariectomized recipients were placed with intact males 2 weeks after transplantation and monitored daily for the presence of a vaginal plug. They were killed by cervical dislocation: (I) immediately after parturition if they had become pregnant within 6 weeks of transplantation: (2) immediately after plugging for the third time if they had not become pregnant by 6 weeks after transplantation; or (3) 6 weeks after transplantation if no vaginal plug was observed during this period. Control bilaterally ovariectomized adult mice were killed 6 weeks after transplantation.

Unilaterally ovariectomized recipients were initially placed with vasectomized males 2 weeks after transplantation to allow the transplanted ovaries to develop uninterrupted from a pregnancy occurring as a result of ovulations from the remaining intact ovary of the recipient. The recipients were monitored daily for the presence of a vaginal plug. They were divided into three groups: (1) The vasectomized male was left with the female until plugging for the third time, if it occurred more than 6 weeks after transplantation, after which the female was killed; (2) The vasectomized male was replaced with an intact male at the same time after transplantation that the earliest pregnancy occurred in the bilateral transplant recipients. The females were killed at day 17-18 of pregnancy to observe in which uterine horn the fetuses were located to determine from which ovary the fetuses arose. (3) Recipients were killed 6 weeks after transplantation if no vaginal plugs were observed during this period.

Heterotopic groups. Bilaterally ovariectomized recipients were placed with intact males 2 weeks after transplantation and monitored daily for the presence of vaginal plugs. Unilaterally ovariectomized and intact recipients were placed with vasectomized males. Six mice from each group were killed by cervical dislocation at 2, 4,6 and 8 weeks after transplantation. Control bilaterally ovariectomized adult mice $(n=15)$ were killed 6 weeks after bilateral ovariectomy.

\section{Histological examination of ovaries}

Ovarian tissue was placed into Bouin's solution for $24 \mathrm{~h}$ and prepared as paraffin-embedded blocks. Serial sections were cut at $7 \mu \mathrm{m}$ thickness and stained with haematoxylin and eosin. Sections representing the 20th, 50th and 80th percentiles of the total number of sections cut, were examined for primary, secondary and Graafian follicles and corpora lutea.

\section{Statistical analysis}

The results were analysed using chi-squared analysis $(P<0.05$ equals significance) comparing pregnancy between groups. Results are presented as means \pm SEM, or as the percentage of those animals that were cyclic and became pregnant.

\section{Results}

\section{Orthotopic transplantation of unfrozen 16-day fetal ovaries}

In the bilaterally ovariectomized group, all mice that received fetal ovarian grafts started regular oestrous cycles within 6 weeks of transplantation. The earliest time that oestrous cycles started was 15 days after transplantation and the mean time for commencement of cyclic activity was $20.5 \pm 4.7$ days after transplantation. The average number of oestrous cycles for each recipient, during the 6 week observation period after transplantation, was $2.9 \pm 0.3$ cycles of $10.5 \pm 1.4$ days duration (pseudopregnancy). Three out of nine mice became pregnant within $40.3 \pm 6.7$ days after transplantation. All pups were born live and apparently normal. The average litter size of $2.7 \pm 0.9$ pups was not significantly different from the control litters $(4.1 \pm 0.4$ pups $)$. The chronological age of the transplanted fetal ovary at the time pregnancy occurred was $35.3 \pm 6.7$ days. Histological examination showed that the fetal grafts were similar in morphology to normal adult ovaries. Follicles at all stages of folliculogenesis and corpora lutea were observed (Fig. 1).

In the unilateral group, the mean time to the first oestrous cycle was $29.0 \pm 4.6$ days with cyclic activity starting as early as 17 days after transplantation. The average number of oestrous cycles for each recipient, within 6 weeks after transplantation, was $3.0 \pm 0.3$ cycles with each oestrous cycle lasting $10.6 \pm 0.8$ days. Thus, recipients repeatedly became pseudopregnant. All three mice in this group that were placed 


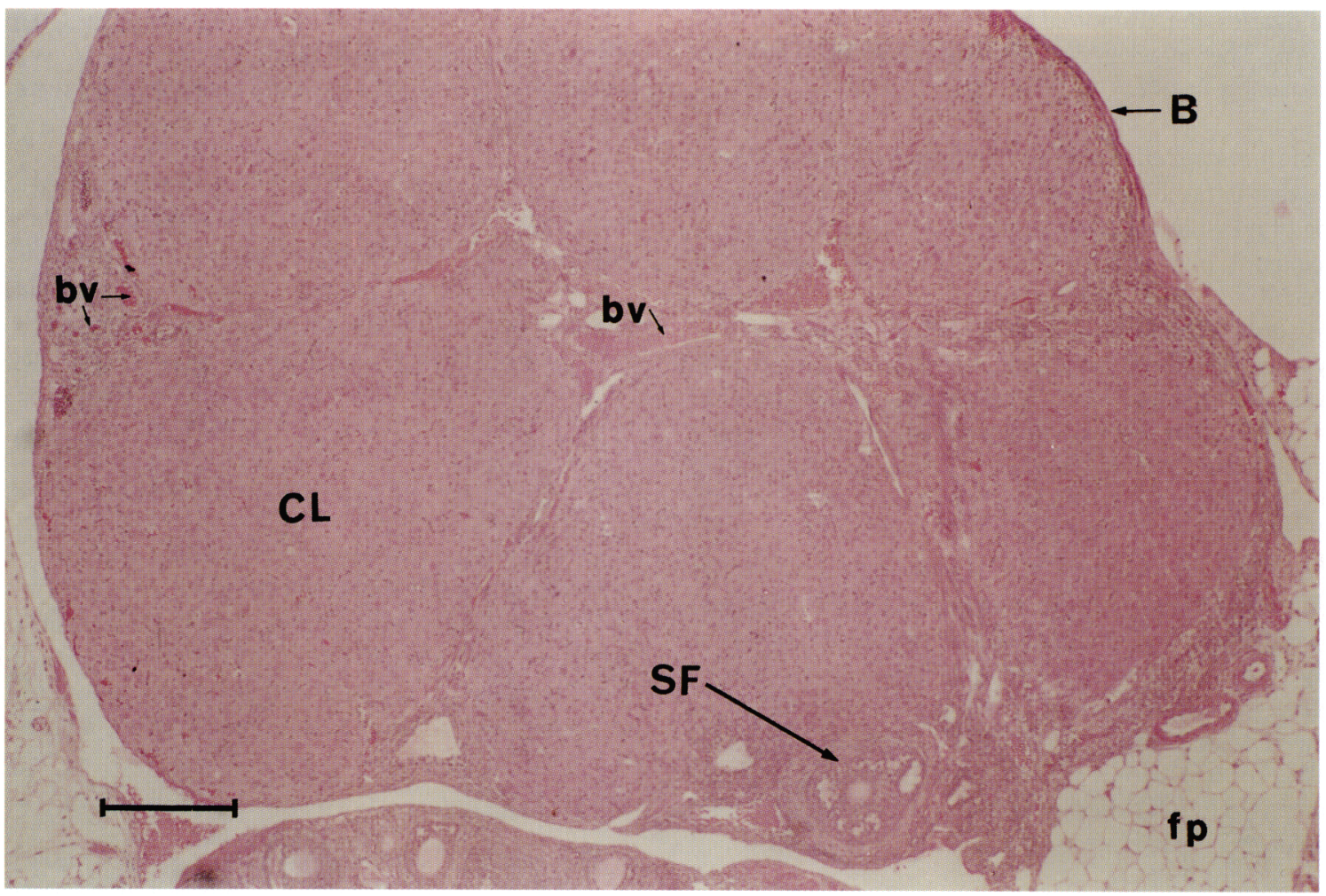

Fig. 1. Morphology of a fresh 16-day-old fetal mouse ovary 6 weeks after orthotopic transplantation to a bilaterally ovariectomized adult female mouse. The graft contained developing follicles at all stages of folliculogenesis and numerous corpora lutea. B: bursa; bv: blood vessel; CL: corpus luteum; SF: secondary follicle; fp: fat pad. Scale bar represents $200 \mu \mathrm{m}$.

with intact males became pregnant within $40.3 \pm 6.7$ days after transplantation. Postmortem examination of these animals at day 17-18 of gestation showed that all fetuses were located in the uterine horn on the side of the remaining intact ovary, indicating that they arose from the recipient's own ovary and not from the fetal graft. Histological examination of the seven unilaterally ovariectomized mice that received fetal ovarian tissue revealed that only one mouse had any ovarian tissue present on the side of the fetal graft. This ovary was similar in size and appearance to an intact adult ovary, displaying follicles at all stages of folliculogenesis and corpora lutea. Of the remaining six mice in this group, no ovarian tissue was observed in the bursal cavity on the side of the fetal graft. The remaining contralateral ovary in all mice exhibited ovarian compensation, increasing in size from $2.0 \mathrm{~mm}$ in the control intact mice to $3.1 \mathrm{~mm}$ in the unilaterally ovariectomized group.

Five out of fifteen mice in the control group showed evidence of the presence of a vaginal plug (one only in each mouse) during the 6-week period that they were observed. None of these mice became pregnant. Histological examination revealed that only one mouse had remnant ovarian tissue present in the bursal cavity.

\section{Heterotopic transplantation of unfrozen 16-day-old fetal ovaries}

In the bilaterally ovariectomized group, all recipients of heterotopic grafts showed regular oestrous cycles as early as 15 days after transplantation. The mean time to the first oestrous cycle was $23.4 \pm 0.8$ days after transplantation. The mean chronological age of the fetal ovary at the commencement of cyclic activity was $18.43 \pm 0.8$ days. The average numbers of oestrous cycles per recipient killed at 4,6 or 8 weeks after transplantation were $1.2 \pm 0.5,1.7 \pm 0.3$ and $1.7 \pm 0.2$ cycles, respectively. Oestrous cycles lasted on average $4.7 \pm 0.9,8.0 \pm 1.1$ and $9.0 \pm 1.1$ days within 4,6 and 8 weeks after transplantation, respectively. Histological examination of ovarian tissue obtained at 2, 4, 6 and 8 weeks after transplantation showed that, by 4 weeks after transplantation, the fetal grafts had grown to the size of an intact adult ovary $(2.0 \mathrm{~mm})$, and contained primordial follicles, developing follicles up to the Graafian follicle stage, and numerous corpora lutea. The fetal grafts also showed a similar appearance at 6 and 8 weeks after transplantation.

In the unilaterally ovariectomized and intact groups in which heterotopic transplants of fetal ovaries were performed, histological examination showed that at 2 weeks after transplantation the fetal graft had doubled in size from $0.45 \mathrm{~mm}$ to $1.0 \mathrm{~mm}$ diameter. No further increase in size of the fetal ovarian grafts was observed at 4,6 and 8 weeks after heterotopic transplantation. All fetal grafts contained developing follicles up to the early antral stage, however, no preovulatory follicles or corpora lutea were observed (Fig. 2). The duration and number of cycles for each recipient were not recorded for the unilaterally ovariectomized or intact recipients. The fifteen control bilaterally ovariectomized mice did not exhibit any oestrous activity or pregnancy. 


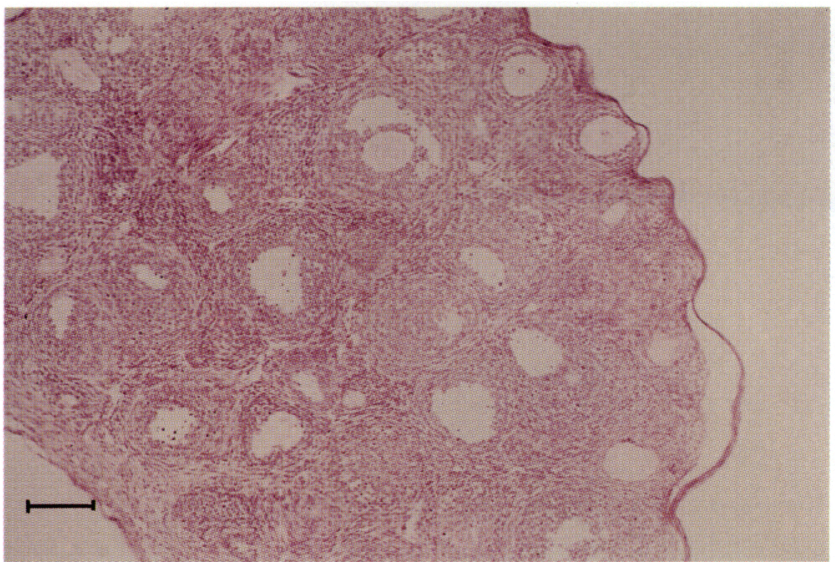

Fig. 2. Appearance of a fresh 16-day-old fetal mouse ovary 4 weeks after heterotopic transplantation to a unilaterally ovariectomized adult female mouse. The graft contained developing follicles but no preovulatory follicles or corpora lutea. Scale bar represents $100 \mu \mathrm{m}$.

\section{Orthotopic transplantation of frozen-thawed 16 day fetal ovaries}

All bilaterally ovariectomized mice that received frozenthawed fetal ovarian grafts showed regular oestrous cycles which started as early as 15 days after transplantation. The mean times to the first oestrous cycle were $19.3 \pm 2.1$ and $23.4 \pm 5.1$ days after transplantation in the slow thaw and fast thaw groups, respectively. The mean numbers of oestrous cycles per recipient, within 6 weeks after transplantation, were $3.1 \pm 0.5$ and $3.3 \pm 0.5$ cycles in the fast and slow thaw groups, respectively. The mean durations of each oestrous cycle were $8.4 \pm 0.9$ and $9.25 \pm 1.3$ days in the fast and slow thaw groups, respectively. The earliest pregnancy observed in these groups was at 23 days after transplantation. The mean times to pregnancy were $28.0 \pm 1.0$ and $36.3 \pm 4.6$ days after transplantation in the slow thaw and fast thaw groups, respectively. There was no significant difference in the time to the onset of pregnancy between orthotopically transplanted fresh and frozen fetal ovaries. Significantly more pregnancies $(P<0.05)$ occurred in recipients of fast thawed fetal ovaries than in recipients of slowly thawed ovaries $(86 \%$ and $25 \%$, respectively). Histological examination showed that all transplanted fetal grafts in both the slow and fast thaw groups contained follicles at all stages of development and numerous corpora lutea and had grown to approximately $1.8 \mathrm{~mm}$ in diameter compared with control adult ovaries which had grown to $2.0 \mathrm{~mm}$ in diameter (Fig. 3). Evidence of freeze-thaw injury was observed in fetal ovaries fixed immediately after thawing in both groups. The epithelium of the ovaries after freezing and thawing was partially (fast thaw group) or completely (slow thaw group) disrupted (Fig. 4).

In the unilaterally ovariectomized group, the average numbers of oestrous cycles exhibited by the recipients were $3.1 \pm 0.3$ and $2.8 \pm 0.4$ cycles in the fast and slow thaw groups, respectively. Oestrous cycles lasted $11.5 \pm 1.2$ and $10.3 \pm 0.8$ days (pseudopregnancy) in the fast and slow thaw groups, respectively. All three recipients placed with intact males became pregnant. However, at postmortem at 17-18 days of gestation, all fetuses were located in the uterine horn associated with the ovaries of the hosts. Histological examination of the
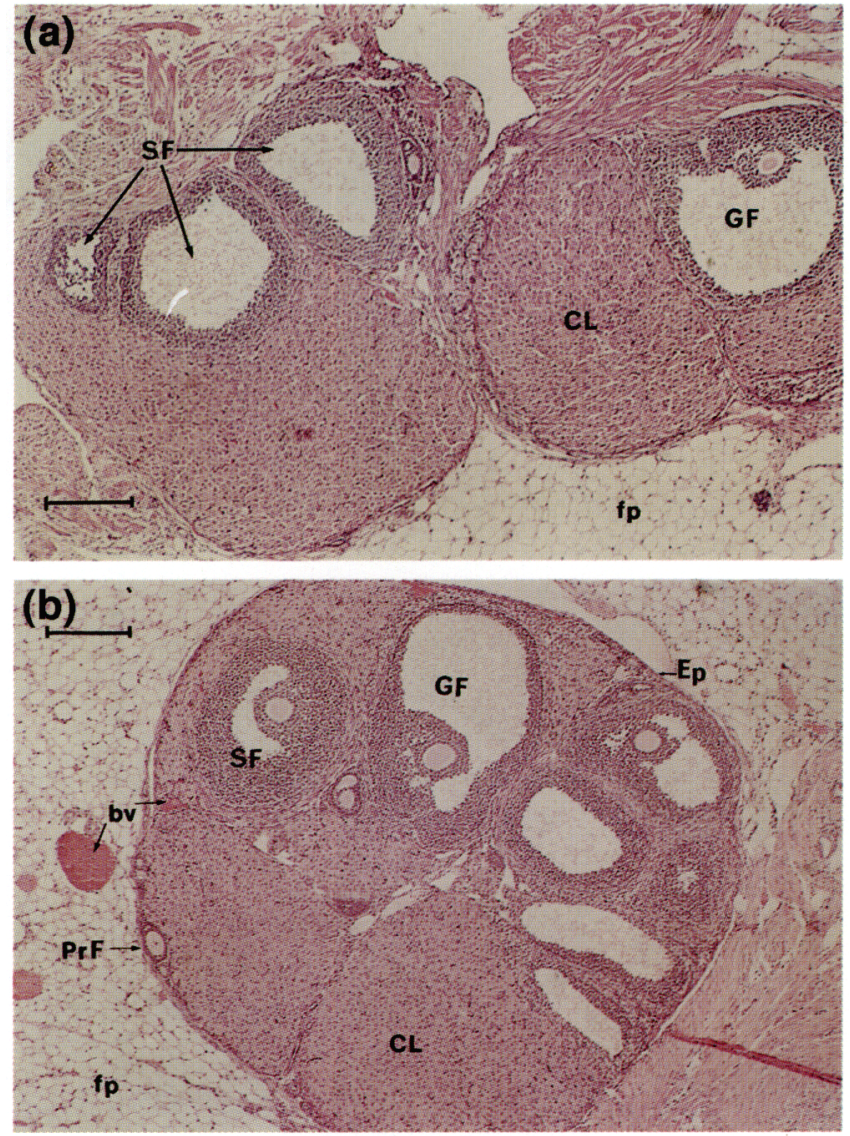

Fig. 3. Morphology of frozen-thawed 16-day-old fetal mouse ovaries (a) fast thawed (b) slow thawed, 6 weeks after orthotopic transplantation to bilaterally ovariectomized adult female mice. The ovarian graft displayed developing follicles and corpora lutea. SF: secondary follicle; CL: corpus luteum; fp: fat pad; GF: Graafian follicle; Ep: epithelium; bv: blood vessel; PrF: primary follicle. Scale bar represents $200 \mu \mathrm{m}$.

graft site failed to locate any ovarian tissue derived from the fetal graft in the slow thaw group $(n=7)$. Fetal ovarian tissue was present on the side of the graft in only one of the seven mice in the fast thawed group. In this recipient, the fetal graft had not increased in size, although developing follicles up to the antral stage were observed (Fig. 5). None of the remaining mice in the fast thawed group had ovarian tissue observable on the side of the fetal graft.

\section{Discussion}

This study shows, for the first time, that the fertility of ovariectomized adult female recipients can be restored by grafts of both fresh and frozen-thawed fetal mouse ovaries. It was found that fresh or frozen-thawed fetal ovaries showed accelerated maturation and gave rise to live young only when transplanted to bilaterally ovariectomized adult recipients. It is known that the concentrations of circulating gonadotrophins rise after bilateral ovariectomy in mice (Naik et al., 1984). The rise in concentrations of gonadotrophins may have provided the stimulus responsible for the accelerated maturation of 


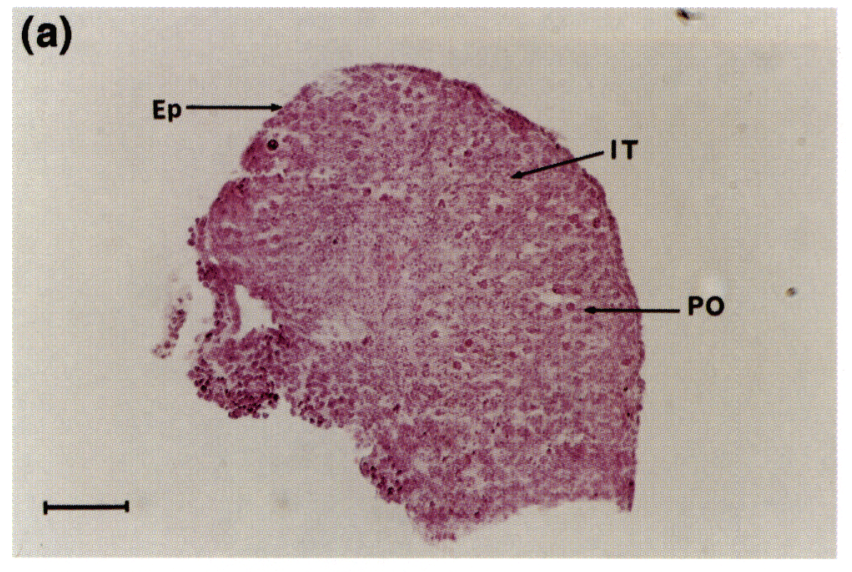

(b)
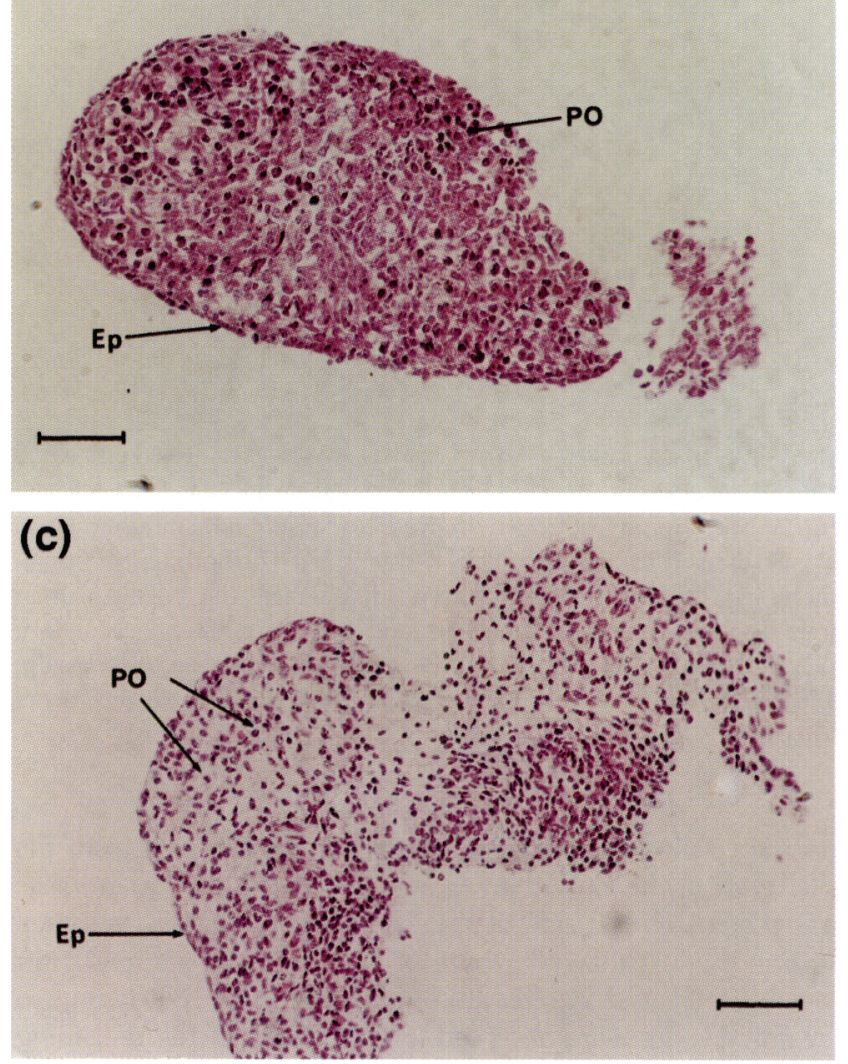

Fig. 4. Morphology of fresh and frozen-thawed 16-day-old fetal mouse ovaries (a) fresh, (b) fast thawed, and (c) slow thawed fixed immediately after thawing. Disruption of the epithelium of the fetal ovary is evident after freezing and thawing. PO: primordial follicles; Ep: epithelium; IT: interstitial tissue. Scale bars represent $50 \mu \mathrm{m}$.

the fetal ovaries transplanted to bilaterally ovariectomized recipients.

All fetal grafts (orthotopic and heterotopic) that were transplanted into recipients in which one or both ovaries remained intact either failed to become established or failed to develop fully. One possible explanation for the failure of fetal grafts to develop in the presence of adult ovarian tissue could be that the recipient's own ovaries either directly or indirectly inhibited the development of the fetal ovary. Factors secreted

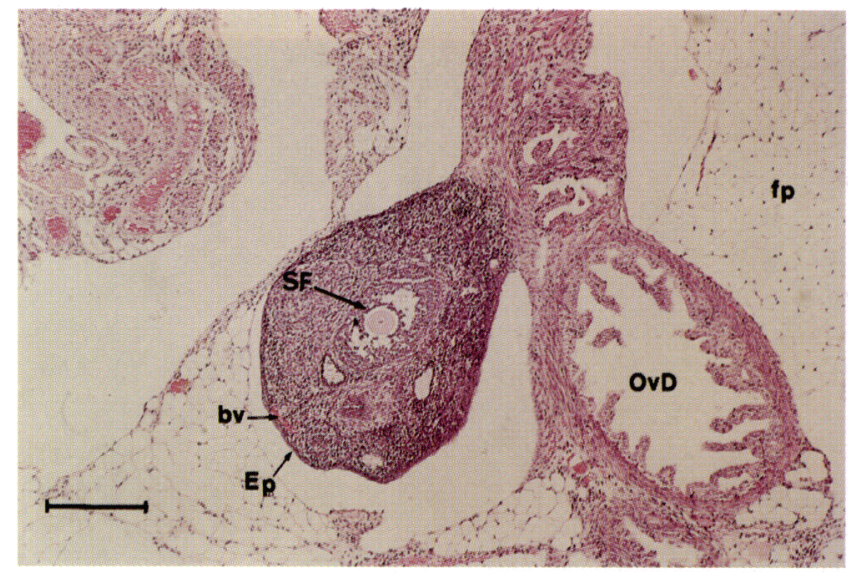

Fig. 5. Histology of the frozen-thawed 16-day-old fetal mouse ovary found in only one mouse in the fast thaw group 6 weeks after orthotopic transplantation to a unilateral ovariectomized adult female mouse. This section shows that the fetal graft had not grown in size, although it did contain developing follicles. No corpora lutea were observed. Ep: epithelium; bv: blood vessel; SF: secondary follicle; OvD: oviduct; fp: fat pad. Scale bar represents $100 \mu \mathrm{m}$.

by the intact adult ovaries such as oestrogen, progesterone or inhibin may have directly or indirectly arrested development of the fetal ovary. Another possibility is that the concentration of circulating gonadotrophins in the intact or unilaterally ovariectomized adult recipients was not adequate to initiate the development of the fetal ovary. In a study by Deanesly (1956), ovaries from 7-10 day old rats were transplanted subcutaneously to unilaterally ovariectomized adult female rats. The neonatal rat ovaries showed retarded development, contained numerous primordial follicles but did not contain corpora lutea. Deanesly (1956) concluded that this retarded development was due to reduced gonadotrophin concentrations. However, these results do not rule out the possibility that the recipient's own ovary directly controlled development of the fetal graft.

The completeness of the ovariectomy procedure used in this study was evident since none of the control bilaterally ovariectomized females became pregnant. One mouse did show traces of ovarian tissue remaining in the bursal cavity but this minimal amount of tissue did not produce a pregnancy. Five out of the fifteen control mice did, however, show the presence of one vaginal plug soon after introduction of the male. This may be attributed to males mounting these females on first introduction since no further mating activity was observed in these animals. The ovariectomy procedure in this study has also been successfully used by previous investigators to study the longevity of ovarian grafts (Jones and Krohn, 1960) and to produce lines of transgenic mice from founder females that are infertile or terminally ill (Bren et al., 1990).

Accelerated maturation of fetal grafts transplanted to bilaterally ovariectomized recipients was first reported when the first fetal transplants were performed by Fò (1900). In the present study, the fetal ovary became hormonally functional, demonstrated by the presence of vaginal plugs, as early as I5 days after transplantation, with the first fertile mating occurring as early as 23 days after transplantation to bilaterally ovariectomized adult females. In adult rodents it takes approximately 22-23 days for a primordial follicle recruited from the 
reserve pool of follicles to reach the stage of ovulation (Driancourt et al., 1993). Hence, the fetal ovary reached 'puberty' in some animals earlier than it would have if it had been left in situ. It is thus proposed that an inhibitor, present in the fetus, is normally responsible for the relative quiescence of the fetal ovary during fetal development and that the ovary is released from this inhibition when transplanted into an adult.

The site of grafting was important in ensuring survival of the fetal ovary. Transplantation of the fetal graft to the kidney capsule caused more rapid development than did transplantation to the bursal cavity. The kidney capsule is highly vascularized and is known to contain high concentrations of angiogenic factors such as vascular endothelial growth factor (Jakeman et al., 1992). Both of these factors would aid in revascularization of the graft after transplantation.

In this study we have shown for the first time that, after cryopreservation, transplanted primordial follicles contained within the fetal ovaries were capable of folliculogenesis, steroidogenesis, ovulation and formation of corpora lutea, resulting in the birth of live young. Past attempts at freezing adult ovarian tissue have shown that the primordial follicles from rats and sheep are virtually the sole surviving follicles (Deanesly, 1954; Gosden et al., 1994). However, studies in adult marmoset monkeys have shown that follicles ranging from the primordial to the small and large antral stage were present in previously frozen ovarian tissue explants before and after transplantation (Candy et al., 1995).

An optimal rate of thawing is important in cryopreservation of cells and tissues to minimize loss of potentially viable cells. This study has shown that fetal ovaries that were slowly frozen and fast thawed achieved significantly more pregnancies than did fetal ovaries that were slowly frozen and slow thawed. Slow cooling was halted at $-40^{\circ} \mathrm{C}$, at which point the tissue may have still been partially hydrated. These findings parallel those obtained by Shaw et al. (1995a, b) using embryos. It is known that embryos that are not fully dehydrated are injured if the thawing rate is too slow since ice crystals have time to form and grow within the cell during warming (Mazur et al., 1972; Shaw et al., 1995a, b). In the present study, damage resulting from the formation of ice crystals within the slowly thawed fetal ovaries may have contributed to the lower pregnancy rates in this group.

Alternatively, the lower pregnancy rates seen in the slow thawing group may have occurred as a result of damage to the epithelium surrounding the fetal ovary during cryopreservation. Damage was more severe in the group that underwent slow thawing. Loss of the epithelium may have led to adhesions between the fetal graft and surrounding structures which would effect capture of oocytes by the fimbria at ovulation.

This study has shown that cryopreservation of fetal ovarian tissue has the potential to allow the storage of large numbers of viable female germ cells which can restore fertility to bilaterally ovariectomized adult females after transplantation. This method could also be used for preserving genetic material from endangered and transgenic animais and for increasing productivity in superior livestock. The transplantation of fetal ovarian tissue to the adult will also aid in our understanding of the control of development in the mammalian ovary.
The research reported in this study was supported by an Australian Research Council grant to G. Jenkin and a Monash IVF grant to J. Shaw and G. Jenkin. The assistance of M. Schneider-Kolsky with the histological studies and conceptual discussions with $\mathrm{R}$. Webb are acknowledged.

\section{References}

Baker TG (1971) Radiosensitivity of mammalian oocytes with particular reference to the human female American Journal of Obstetrics and Gynecology $110746-761$

Ben-or S (1965) Morphological and functional development of the ovary of the mouse. II. The development of the ovary in transplantation conditions in adult spayed hosts Journal of Embryology and Experimental Morphology 14 I11-118

Bren G, Buanack E, Müller M and Winnaker E-L (1990) Transgenic offspring by transcaryotic implantation of transgenic ovaries into normal mice Molecular Reproduction and Development 25 42-44

Candy CJ, Wood MJ and Whittingham DG (1995) Follicular development in cryopreserved marmoset ovarian tissue after transplantation Human Reproduction 10 2334-2338

Carroll J, Whittingham DG and Wood MJ (1991) Effect of gonadotrophin environment on growth and development of isolated mouse primary ovarian follicles Journal of Reproduction and Fertility 93 71-79

Deanesly R (1954) Immature rat ovaries grafted after freezing and thawing Journal of Endocrinology 11 197-200

Deanesly R (1956) Cyclic function in ovarian grafts Journal of Endocrinology 13 211-220

Donovan BT and Peddie MJ (1973) The development of fetal and infant guinea pig gonadal tissue in adult host Journal of Reproduction and Fertility 35 $582-583$

Driancourt MA, Gougeon A, Royère D and Thibault C (1993) Ovarian function. In Reproduction in Mammals and Man p 286 Eds C Thibault, MC Levasseur and RHF Hunter. Ellipse, Paris

Fòa C (1900) La Graffe des ovaries en relation avec aquelques questions de biologie generale Archives Italiennes de Biologie 34 43-73 cited in Gosden RG (1992) Transplantation of ovaries and testes. In Fetal Transplants in Medicine pp 253-274 Ed. RG Edwards. Cambridge University Press, Cambridge

Gosden RG (1992) Transplantation of fetal germ cells Journal of Assisted Reproduction and Genetics 9 118-123

Gosden RG, Baird DT, Wade JC and Webb R (1994) Restoration of fertility to oophorectomised sheep by ovarian autografts stored at - 196 degrees $C$ Human Reproduction 9 597-603

Green SH, Smith AV and Zuckerman S (1956) The numbers of oocytes in ovarian autografts freezing and thawing Journal of Endocrinology 13 330-334

Harris M and Eakin EM (1949) Survival of transplanted ovaries in rats Journal of Experimental Zoology 112 131-163

Holyoke EA (1956) The differentiation of embryonic ovaries and testes grafted together in adult hosts in the rabbit Anatomical Records 124307

Jakeman LB, Winer J, Bennett GL, Altar CA and Ferrara N (1992) Binding sites for vascular endothelial growth factor are localised on endothelial cells in adult rat tissues Journal of Clinical Investigation $\mathbf{8 9} 244-253$

Jones EC and Krohn PL (1960) Orthotropic transplantation in mice Journal of Endocrinology 20 135-146

Mangoushi MA (1974) The fate of grafted fetal ovaries in the rat Journal of Anatomy 118 601-610

Mangoushi MA (1977) Contiguous allografts in the male and female gonadal primordia in the rat Journal of Anatomy 123 407-413

Mazur P, Leibo S and Chu EHY (1972) A two-factor hypothesis of freezing injury Experimental Cell Research 71 345-355

Naik SI, Young LS, Charlton HM and Clayton RN (1984) Pituitary gonadotropinreleasing hormone receptor regulation in mice. II: Females Endocrinology 115 $114-120$

Povlsen CO, Skakkebaek NE, Rygaard J and Jensen G (1974) Heterotransplantation of human foetal organs to the mouse mutant nude Nature 248 247-249

Robertson GG (1942) An analysis of the development of homozygous yellow mouse embryos Journal of Experimental Zoology 89 197-227

Rumery WL and Blandeau RJ (1976) The response of transplants of cultured fetal mouse ovaries in kidneys of ovariectomised adult mice Journal of Morphology 149 421-436 
Russell WL and Douglass PM (1945) Offspring from unborn mothers Proceetings of the National Academy of Science Washington 31 402-404

Russell WL and Hurst JG (1945) Pure strain mice born to hybrid mothers following ovarian transplantation Proceedings National Academy of Science Washington 31 267-273

Shaw IM, Ward C and Trounson AO (1995a) Evaluation of propanediol, ethylene glycol, sucrose and antifreeze proteins on the survival of slow cooled mouse pronuclear and 4-cell embryos Human Reproduction 10 396-402

Shaw JM, Ward C and Trounson AO (1995b) Survival of mouse blastocysts slow cooled in propanediol or ethylene glycol is influenced by the thawing procedure, sucrose and antifreeze proteins Theriogenology 43 1289-1300

Sherwood L (1989) Human Physiology: from Cells to Systems. West Publishing Company, St Paul 